\title{
Retina and Choroid of Diabetic Patients Without Observed Retinal Vascular Changes: A Longitudinal Study
}

\author{
JOANA TAVARES FERREIRA, RITA PROENÇA, MARTA ALVES, ARNALDO DIAS-SANTOS, \\ BRUNO OLIVEIRA SANTOS, JOÃO PAULO CUNHA, ANA LUÍSA PAPOILA, AND LUÍS ABEGÃO PINTO
}

- PURPOSE: To identify changes in choroidal thickness (CT) and all retinal layers of diabetic patients without diabetic retinopathy (DR) after 1 year of follow-up.

- DESIGN: Prospective observational cohort study.

- METHODS: Overall, 125 diabetic patients without DR were included. Two visits were scheduled: the first visit (V1) and a second visit after 12 months (V2). At both visits, patients received a complete ophthalmologic evaluation that included OCT. Each retinal layer thickness was calculated for 9 ETDRS sectors, and CT was measured at 13 locations. Generalized linear mixed-effects models were used.

- RESULTS: Of the 125 patients, 103 completed the study, and 9 of the 103 developed DR (8.7\%). CT was significantly higher at $\mathrm{V} 2$ than at $\mathrm{V} 1$, with an average value of $10-17 \mu \mathrm{m}$ at almost half the locations $(500$, 1000, and $1500 \mu \mathrm{m}$ temporal; 500 and $1000 \mu \mathrm{m}$ nasal; and $1000 \mu \mathrm{m}$ superior to the fovea $)(P<.001-.003)$. The thicknesses of the ganglion cell layer (I3 and N6 sectors), inner plexiform layer (S6 and N6 sectors), inner nuclear layer (T6 and N6 sectors), and outer plexiform layer ( 66 sector), as well as the overall retinal thickness (RT) (S3, N3, I3, S6, and T6 sectors), were decreased at V2 $(P<.001)$. Visible retinopathy was negatively associated with overall RT (central, S3, T3, I3, and N3 sectors, $P=.004-.024$ ) and the thickness of the ONL (T6 and I6 sectors, $P=.007$ and $P=.009$ ) and photoreceptor layer ( $\mathrm{N} 6$ sector, $P=.038$ ). The presence of DR decreased the overall RT by $13.04-16.63 \mu \mathrm{m}$.

- CONCLUSIONS: Diabetic patients without DR showed a thicker choroid and a thinner retina, particularly in inner

\footnotetext{
AJO.com

Supplemental Material available at AJO.com.

Accepted for publication Dec 23, 2016.

From the Department of Ophthalmology (J.T.F., R.P., A.D.-S., J.P.C.) and the Epidemiology and Statistics Unit, Research Centre (M.A., A.L.P.), Central Lisbon Hospital Center, Lisbon, Portugal; NOVA Medical School, Universidade NOVA de Lisboa, Lisbon, Portugal (J.T.F., A.D.-S., J.P.C., A.L.P.); Department of Ophthalmology, Associação Médica Olhar bem, Lisbon, Portugal (B.O.S.); CEris-ICIST, Instituto Superior Técnico (B.O.S.), Visual Sciences Study Center, Faculty of Medicine (L.A.P.), and CEAUL (Center of Statistics and Applications) (A.L.P.), Lisbon University, Lisbon, Portugal; and Department of Ophthalmology, Northern Lisbon Hospital Center, Lisbon, Portugal (L.A.P.).

Inquiries to Joana Tavares Ferreira, Department of Ophthalmology, Hospital de Santo António dos Capuchos, Alameda de Santo António dos Capuchos, 1169-050 Lisboa, Portugal; e-mail: joanaptf@gmail.com
}

layers, after 1 year of follow-up. These structural changes may correspond to the early neurodegenerative phase of DR. (Am J Ophthalmol 2017;176:15-25. (C) 2016 Elsevier Inc. All rights reserved.)

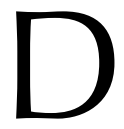
IABETIC RETINOPATHY (DR) IS THE LEADING cause of legal blindness among working-age adults in the United States. ${ }^{1}$ Of the 415 million diabetic patients worldwide in 2015, over one third will develop DR in their lifetime. ${ }^{2}$ The RETINODIAB study, an epidemiologic study that investigated the prevalence and progression rates of DR based on a national screening community program in Portugal, identified a $16.3 \%$ prevalence rate of DR and a $4.6 \%$ incidence rate of any DR within the first year in diabetic patients without retinopathy at baseline. ${ }^{3,4}$

Socioeconomic studies have revealed that the healthcare costs for patients with DR are almost twice the costs for diabetic patients without DR. ${ }^{5,6}$ Furthermore, despite good metabolic control, the rate of DR progression and the risk for vision loss vary among patients. ${ }^{7}$ Therefore, it is important to identify diabetic patients at risk of developing DR.

The International Clinical Classification of DR is based on the observation of microvascular retinal changes. ${ }^{8}$ However, diabetic neuroretinal degeneration has been demonstrated in histologic studies and through the measurement of functional loss with a number of functional tests, including contrast vision, color vision, visual field, dark adaptation, and electroretinogram. These retinal neurodegenerative changes include apoptosis of several populations of retinal cells (eg, photoreceptors, bipolar cells, ganglion cells, and astrocytes) with consequent effects on the thickness of different retinal layers in the earliest stages of DR or when DR cannot be detected by ophthalmologic examination. ${ }^{9-12}$ Furthermore, it has been hypothesized that changes in the choriocapillaris may precede the development of DR. ${ }^{13}$ However, the relationship between DR and diabetic choroidopathy remains unclear.

In vivo, spectral-domain optical coherence tomography (SDOCT) enables reliable and reproducible visualization of the retinal and choroidal layers and measurement of the thickness of each layer. ${ }^{14,15}$ Using this approach, 

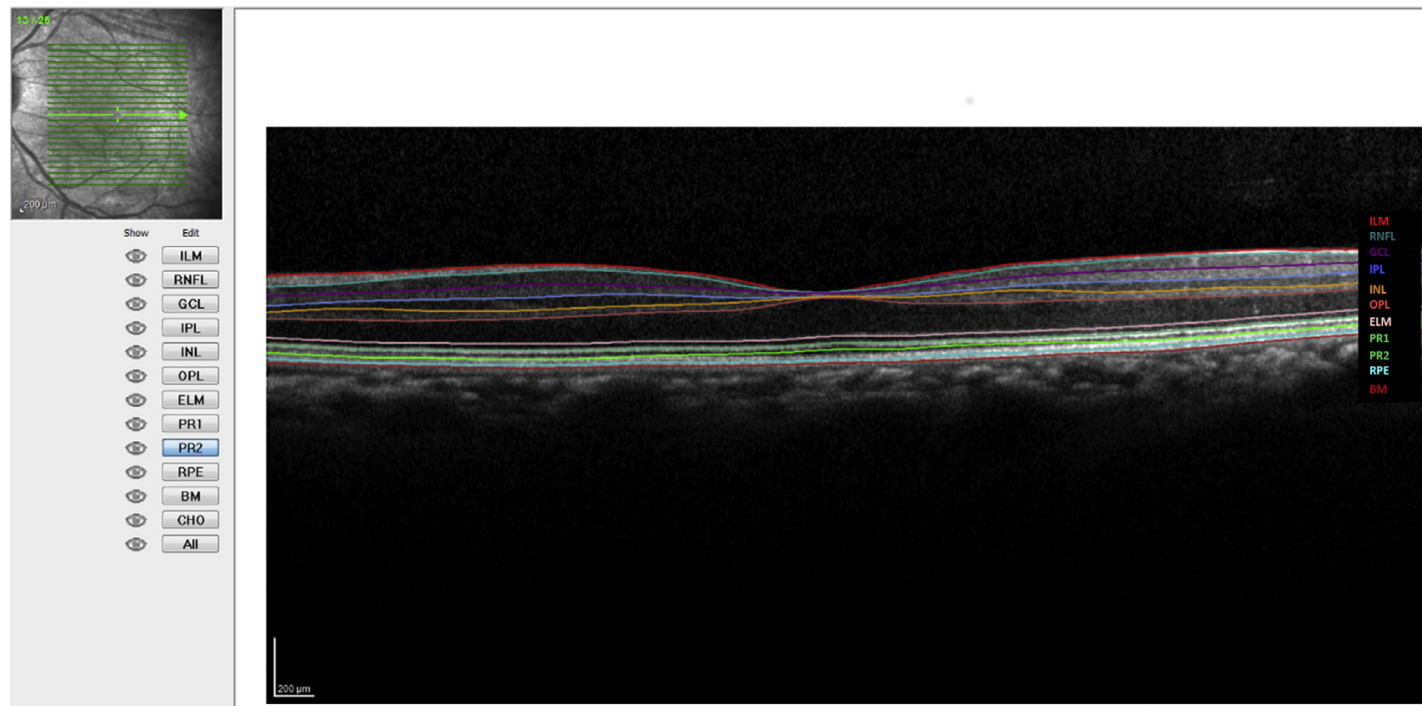

FIGURE 1. Retinal layer segmentation obtained with Spectralis automatic segmentation software.

early retinal neurodegeneration may be detected and the results used to plan preventive therapy before the development of vascular lesions that are detectable by ophthalmoscopy. ${ }^{16}$ However, published studies with OCT image analysis have not been able to predict whether diabetic patients are at risk for DR. To the best of our knowledge, there are no longitudinal studies of diabetic patients without DR using SDOCT.

Thus, the present longitudinal study aimed to evaluate which diabetic patients without DR would develop DR after 1 year and to use SDOCT to detect changes in retinal and choroidal layers over a period of 1 year.

\section{METHODS}

- PATIENTS: This study was conducted at the Ophthalmology Department of the Central Lisbon Hospital Center and was performed in the context of a prospective, observational study designed to follow eyes/patients without DR for a period of 1 year between October 2014 and December 2015. The results of the baseline study (first visit) and procedures have been previously described. ${ }^{17}$ Two hundred and fifty consecutive type 2 diabetic patients sent to primary care centers for DR assessment as part of a nationwide program were screened for inclusion/exclusion criteria. Per protocol, the diagnosis of type 2 diabetes mellitus (DM) was made following the guidelines of the Portuguese General Health Direction. Type 2 diabetic patients without DR with normotensive eyes and with the ability to understand the study were included. The exclusion criteria were as follows: refractive error $>5$ diopters (D) or/and axial length $>25 \mathrm{~mm}$ in the studied eye, known diagnosis of DR or other retinal diseases, glaucoma or ocular hypertension, uveitis,

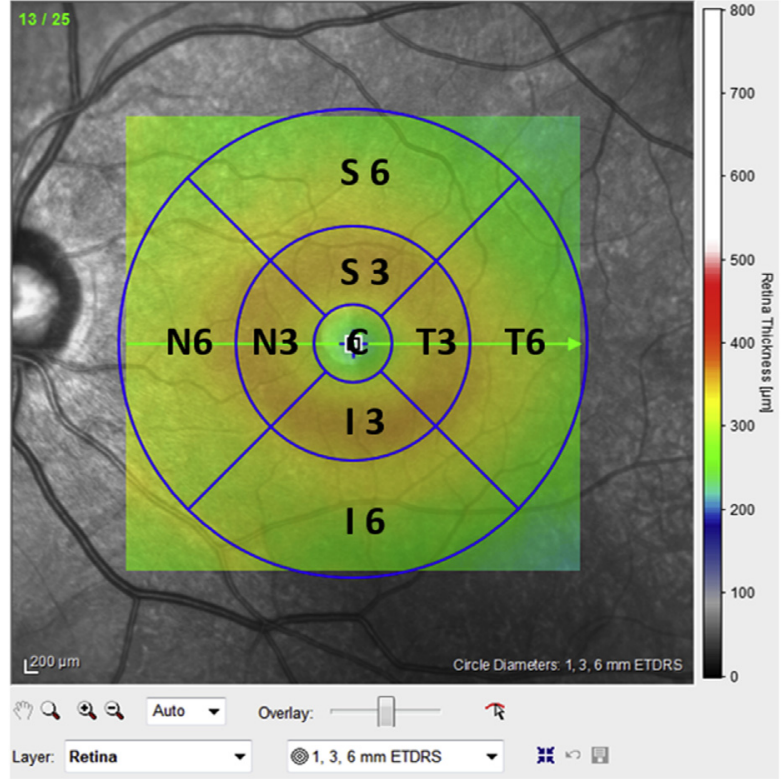

FIGURE 2. Representative Spectralis spectral-domain optical coherence tomography scans of the macular thickness map (Early Treatment Diabetic Retinopathy Study protocol).

neurodegenerative disease, and significant media opacities that precluded fundus imaging.

The study was approved by our institutional ethics committee, and informed consent was obtained from all patients. The study also complied with the principles of the Declaration of Helsinki.

- STUDY PROCEDURES: After screening based on the inclusion/exclusion criteria, a total of 125 type 2 diabetic patients without DR were enrolled in this study. 

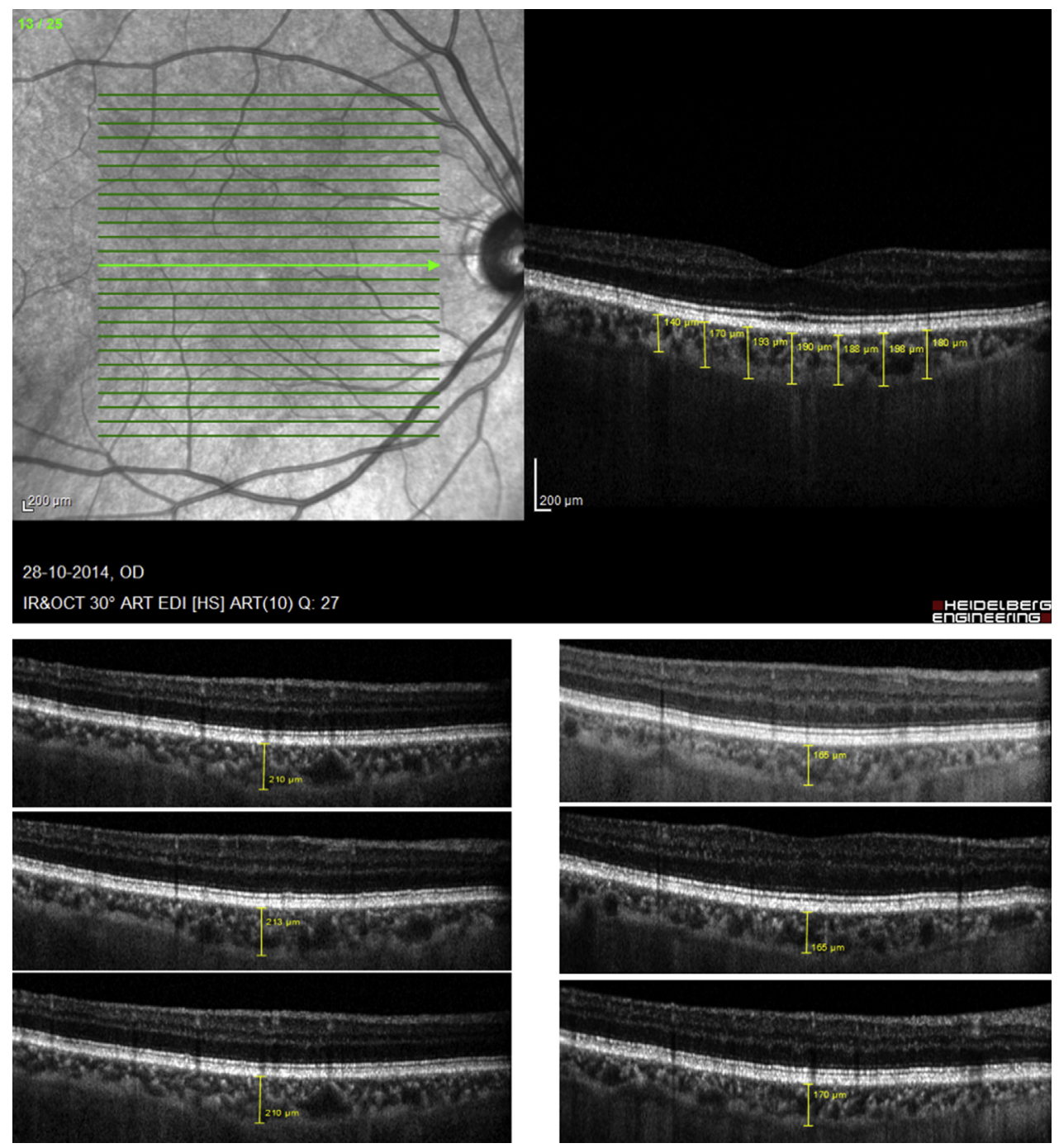

FIGURE 3. Measurements of choroidal thickness at 13 locations: subfoveal (Top right) and at 500- $\mu \mathrm{m}$ intervals from the fovea to $1500 \mu \mathrm{m}$ nasal (Top right), $1500 \mu \mathrm{m}$ temporal (Top right), $1500 \mu \mathrm{m}$ superior (Bottom left), and $1500 \mu \mathrm{m}$ inferior (Bottom right).

The patients performed 2 study visits: V1 (month 0 ) and V2 (month 12). At each visit, the clinical history and the following examinations were performed: Goldmann applanation and dynamic contour tonometries, fundus photography, and SDOCT. The patients' blood pressure (BP) was also assessed. Furthermore, the diabetic patients were asked to provide blood samples for a fasting glucose test on the day of each study visit. One random eye per patient was selected for the study.

Visual Acuity. Best-corrected distance visual acuity (BCVA) for each eye was measured using Snellen charts and converted to the logarithm of the minimum angle of resolution (logMAR).

Intraocular Pressure. Intraocular pressure (IOP) was measured before pupillary dilation with Goldmann applanation and dynamic contour tonometries. For this tonom- etry, a Pascal tonometer was used for the measurement, and IOP values with a quality score less than or equal to 2 were accepted.

Fundus Photography. The pupils were dilated, and after funduscopy with a 90 D Volk lens (Volk company, Mentor, Ohio, USA), 2 fundus photographs were taken, including 1 centered on the fovea and another on the optic disc, using a Topcon TRC 50dx - type 1A camera (Topcon company, Tokyo, Japan).

Spectral-Domain Optical Coherence Tomography Imaging and Layer Segmentation. Tomographic images were obtained using Spectralis SDOCT (Heidelberg Engineering, Heidelberg, Germany; software version 6.0) after pupillary dilation by a single, well-trained technician (G.A.), as described previously. ${ }^{18}$ All OCT examinations were performed at the same time of day from $2 \mathrm{PM}$ to $4 \mathrm{PM}$. 


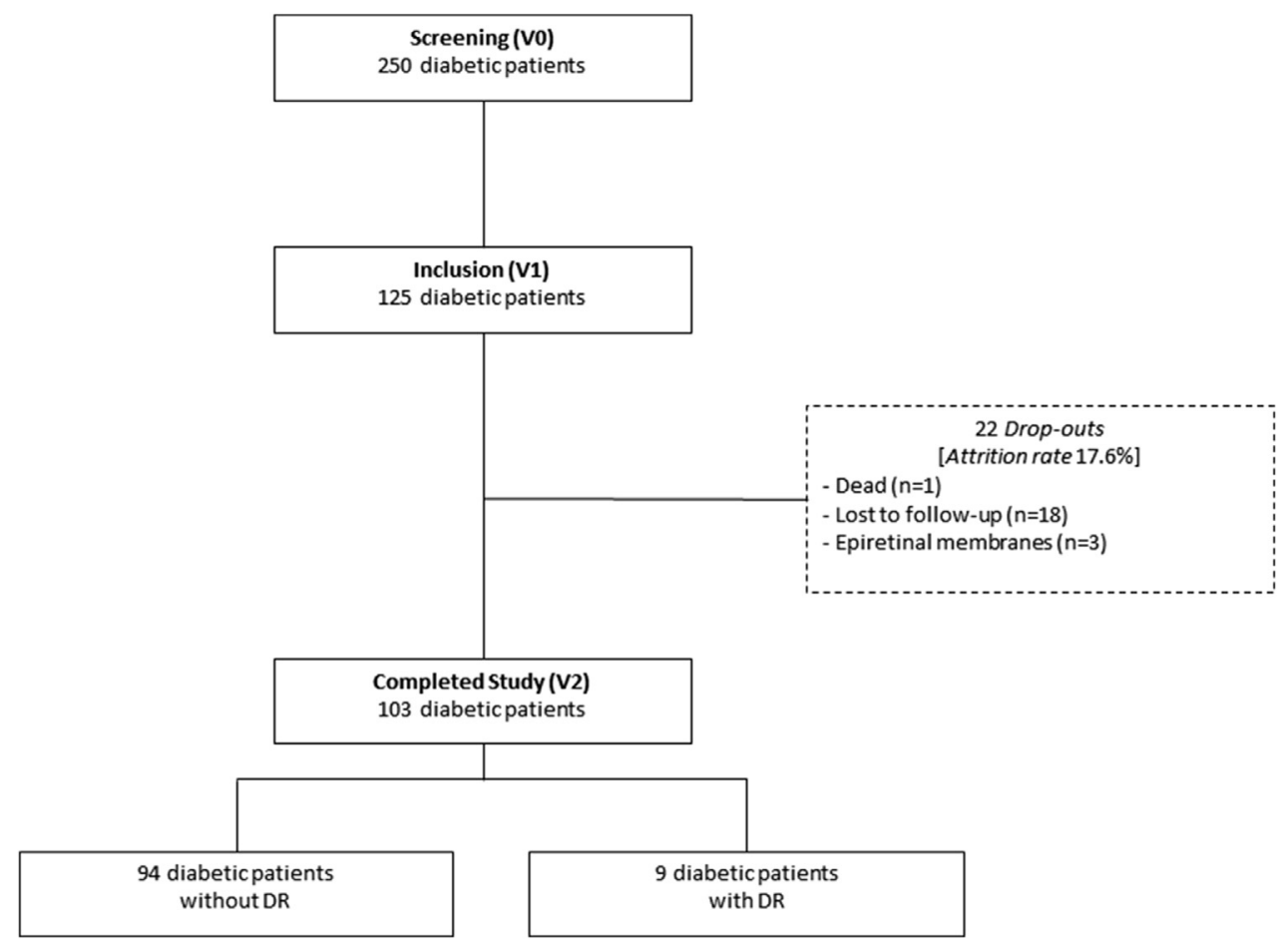

FIGURE 4. Flow chart of study patients through follow-up.

TABLE 1. Patients' Demographic and Clinical Characteristics in the 2 Visits

\begin{tabular}{|c|c|c|c|}
\hline & \multirow{2}{*}{$\frac{\text { Visit } 1}{\text { Diabetic Patients }(\mathrm{N}=125)}$} & \multicolumn{2}{|c|}{ Visit 2} \\
\hline & & Diabetic Patients Without DR $(\mathrm{N}=94)$ & Diabetic Patients With DR $(\mathrm{N}=9)$ \\
\hline Male sex, n (\%) & $63.00(50.40)$ & $49.00(52.10)$ & $4.00(44.40)$ \\
\hline Age $(y)$ & $66.90(9.33)$ & $66.54(8.76)$ & $75.33(8.46)$ \\
\hline BCVA (logMAR) & $0.05(0.10)$ & $0.05(0.08)$ & $0.02(0.03)$ \\
\hline IOP - Goldmann (mm Hg) & $16.28(3.08)$ & $16.43(2.86)$ & $17.22(2.33)$ \\
\hline IOP - Pascal (mm Hg) & $19.06(3.56)$ & $18.83(3.00)$ & $18.27(2.45)$ \\
\hline OPA & $2.80(2.30-4.20)$ & $2.95(2.38-4.13)$ & $2.70(2.15-4.15)$ \\
\hline Spherical equivalent & $0.63(1.53)$ & $0.60(1.45)$ & $0.13(1.38)$ \\
\hline Axial length (mm) & $23.11(0.81)$ & $23.14(0.79)$ & $23.17(1.21)$ \\
\hline State of lens - phakic, n (\%) & 119.00 (95.20) & $91.00(96.80)$ & $7.00(77.80)$ \\
\hline Diabetes duration (mo) & $60.00(30.00-126.00)$ & $72.00(36.00-132.00)$ & $180.00(90.00-276.00)$ \\
\hline Mean arterial pressure $(\mathrm{mm} \mathrm{Hg})$ & 97.00 (91.50-108.00) & 98.00 (92.75-103.00) & $101.00(96.50-105.50)$ \\
\hline HbA1c (\%) & $6.40(6.00-7.00)$ & $6.50(6.00-7.11)$ & $7.40(6.55-8.05)$ \\
\hline Glycemia (mg/dL) & $137.00(118.00-156.00)$ & $130.00(112.00-145.00)$ & $136.00(112.50-175.00)$ \\
\hline
\end{tabular}

Only good-quality scans with well-focused images, without overt misalignment; continuous scan patterns without missing or blank areas, without artefacts; and a signal strength better than $20(40=$ maximum $)$ were included in the analyses. The fast macular thickness OCT protocol was performed with measurements from $20 \times 20$-degree raster scans (consisting of 25 high-resolution scans).
The automatic real-time (ART) function was set to 9 frames per B-scan. An internal fixation light was used to center the scanning area on the fovea while the eyetracking system was activated.

The new Spectralis automatic segmentation software was used to obtain individual retinal layer thickness measurements, including the following: overall retinal 
TABLE 2. Choroidal Thickness $(\mu \mathrm{m})$ in 13 Locations at Visits 1 and 2

\begin{tabular}{|c|c|c|c|c|}
\hline & \multirow{2}{*}{$\frac{\text { Visit } 1}{\text { Diabetic Patients }(N=125)}$} & \multicolumn{2}{|c|}{ Visit 2} & \multirow[b]{2}{*}{$P$ Value } \\
\hline & & Diabetic Patients Without DR $(\mathrm{N}=94)$ & Diabetic Patients With DR $(\mathrm{N}=9)$ & \\
\hline Subfoveal central & 260.68 (65.89) & 271.71 (67.94) & $262.44(60.87)$ & .607 \\
\hline Temporal $500 \mu \mathrm{m}$ & 253.25 (63.88) & 271.88 (67.36) & 251.78 (64.93) & .300 \\
\hline Temporal $1000 \mu \mathrm{m}$ & 245.60 (59.37) & 266.13 (65.62) & 243.89 (57.81) & .319 \\
\hline Temporal $1500 \mu \mathrm{m}$ & 236.17 (57.85) & 254.09 (62.05) & 233.56 (54.17) & .355 \\
\hline Nasal $500 \mu \mathrm{m}$ & 248.78 (66.20) & 263.38 (67.90) & 262.78 (56.73) & .911 \\
\hline Nasal $1000 \mu \mathrm{m}$ & 237.02 (67.99) & 249.69 (69.06) & $245.33(55.04)$ & .866 \\
\hline Nasal $1500 \mu \mathrm{m}$ & $220.81(70.22)$ & $230.28(71.00)$ & 217.00 (53.66) & .579 \\
\hline Superior $500 \mu \mathrm{m}$ & $261.94(66.41)$ & 272.62 (62.90) & 269.56 (63.37) & .776 \\
\hline Superior $1000 \mu \mathrm{m}$ & 262.21 (65.59) & 275.47 (64.46) & 259.11 (61.62) & .389 \\
\hline Superior $1500 \mu \mathrm{m}$ & 267.89 (67.49) & $280.10(64.00)$ & $259.00(60.49)$ & .334 \\
\hline Inferior $500 \mu \mathrm{m}$ & 249.62 (62.44) & 256.70 (62.97) & 250.89 (54.30) & .798 \\
\hline Inferior $1000 \mu \mathrm{m}$ & 248.36 (68.09) & $256.90(68.83)$ & 248.56 (72.95) & .754 \\
\hline Inferior $1500 \mu \mathrm{m}$ & 249.81 (69.57) & 256.62 (72.69) & 242.56 (81.81) & .583 \\
\hline
\end{tabular}

Results are expressed as mean (standard deviation). $P$ values were obtained by Mann-Whitney test to compare choroidal thickness between diabetic patients with and without diabetic retinopathy.

thickness (RT), retinal nerve fiber layer (RNFL), ganglion cell layer (GCL), inner plexiform layer (IPL), inner nuclear layer (INL), outer plexiform layer (OPL), outer nuclear layer (ONL), retinal pigment epithelium (RPE), and photoreceptor layer (PR) (Figure 1). The OCT images obtained by the technician were assessed by an ophthalmologist (J.F.) who was masked to the patients' diagnosis; this evaluator verified the automatic segmentation in addition to making corrections with manual segmentation when it was not defined correctly.

In all layers, the thickness values were calculated for 9 Early Treatment Diabetic Retinopathy Study (ETDRS) areas. ${ }^{19}$ The ETDRS plot consisted of 3 concentric rings with 1-, 3-, and 6-mm diameters centered at the fovea. The 2 outer rings were divided into quadrants by 2 intersecting lines. Each sector was designated C, S3, S6, T3, T6, I3, I6, N3, and N6, as shown in Figure 2. The ETDRS grid was positioned automatically with the Spectralis OCT software, which enabled the capture and extraction of the macular thickness values.

The fast macular thickness OCT protocol scans were performed again in enhanced depth imaging (EDI) mode according to a previously reported method. ${ }^{14}$ The choroidal thickness (CT) was manually measured from the outer portion of the hyperreflective line (corresponding to the $\mathrm{RPE}$ ) to the hyporeflective line (corresponding to the sclerochoroidal interface). These measurements were made in the subfoveal choroid and at $500-\mu \mathrm{m}$ intervals from the fovea to $1500 \mu \mathrm{m}$ nasal, $1500 \mu \mathrm{m}$ temporal, $500 \mu \mathrm{m}$ superior, and $1500 \mu \mathrm{m}$ inferior (13 locations) (Figure 3).

Mean Arterial Pressure. BP was measured with the patient in a seated position using an automatic sphygmomanometer.
The systolic and diastolic blood pressures (SBP and DBP) were recorded. The mean arterial pressure (MAP) was calculated using the following formula:

$$
\mathrm{MAP}=\mathrm{DBP}+1 / 3(\mathrm{SBP}-\mathrm{DBP})
$$

- STATISTICAL ANALYSIS: The patient characteristics were described using the mean and standard deviation (SD) or median and interquartile range (IQR: 25th percentile-75th percentile) for continuous variables, as well as frequencies (percentages) for categorical variables. A nonparametric Mann-Whitney test was applied. Generalized linear mixed-effects models were used to identify the variables that explained the variability of thickness of all retinal and choroid layers in diabetic patients who developed DR and those who did not after 1 year of follow-up. All multivariable regression models considered the variables time (V1 and V2), age, sex, diabetes duration, ocular pulse amplitude, IOP-Pascal, axial length, MAP, HbA1c, and spherical equivalent to adjust for the association between having developed, or not developed, DR with layer thickness. Additionally, multivariable regression models for RPE layers in sectors $\mathrm{C}, \mathrm{S} 3, \mathrm{I} 3, \mathrm{~T} 3$, and $\mathrm{N} 3$ also considered the variable CT subfoveal at distances of $1000 \mu \mathrm{m}$ superior, inferior, temporal, and nasal to the fovea, respectively. The normality assumption of the residuals was verified using a Kolmogorov-Smirnov goodness-of-fit test with the Lilliefors correction. Owing to the problem of multiple testing, Bonferroni corrections were applied. A level of $\alpha=0.05$ was considered to be significant. Data were analyzed using STATA 13.0 (Stata Statistical Software: Release 13; 2013; StataCorp LP, College Station, Texas, USA). 
TABLE 3. Multivariable Regression Model Results for Choroidal Thickness

\begin{tabular}{|c|c|c|c|c|}
\hline Model $^{a}$ & Coefficient Estimate & $P$ Value & \multicolumn{2}{|c|}{$95 \%$ Confidence Interval } \\
\hline \multicolumn{5}{|c|}{ Dependent variable: CT subfoveal central } \\
\hline$\Delta \mathrm{CT}$ V2-V1 & 7.903 & .076 & -0.814 & 16.620 \\
\hline Age & -1.961 & .002 & -3.197 & -0.726 \\
\hline Axial length & -18.147 & .008 & -31.636 & -4.657 \\
\hline \multicolumn{5}{|c|}{ Dependent variable: CT $500 \mu \mathrm{m}$ temporal of the fovea } \\
\hline$\Delta \mathrm{CT}$ V2-V1 & 14.718 & $<.001$ & 6.511 & 22.926 \\
\hline Age & -1.983 & .002 & -3.212 & -0.755 \\
\hline Axial length & -15.649 & .022 & -29.063 & -2.235 \\
\hline \multicolumn{5}{|c|}{ Dependent variable: CT $1000 \mu \mathrm{m}$ temporal of the fovea } \\
\hline$\Delta \mathrm{CT}$ V2-V1 & 17.340 & $<.001$ & 8.807 & 25.873 \\
\hline Age & -1.758 & .003 & -2.906 & -0.610 \\
\hline Axial length & -16.126 & .012 & -28.657 & -3.595 \\
\hline \multicolumn{5}{|c|}{ Dependent variable: CT $1500 \mu \mathrm{m}$ temporal of the fovea } \\
\hline$\Delta \mathrm{CT}$ V2-V1 & 15.990 & $<.001$ & 7.612 & 24.368 \\
\hline Age & -1.657 & .003 & -2.753 & -0.560 \\
\hline Axial length & -16.457 & .007 & -28.432 & -4.482 \\
\hline \multicolumn{5}{|c|}{ Dependent variable: CT $500 \mu \mathrm{m}$ nasal of the fovea } \\
\hline$\Delta \mathrm{CT}$ V2-V1 & 13.291 & .001 & 5.612 & 20.971 \\
\hline Age & -1.753 & .005 & -2.990 & -0.515 \\
\hline Axial length & -21.029 & .002 & -34.537 & -7.521 \\
\hline \multicolumn{5}{|c|}{ Dependent variable: CT $1000 \mu \mathrm{m}$ nasal of the fovea } \\
\hline$\Delta \mathrm{CT}$ V2-V1 & 10.010 & .003 & 3.347 & 16.672 \\
\hline Age & -1.635 & .012 & -2.916 & -0.353 \\
\hline Axial length & -23.275 & .001 & -37.270 & -9.282 \\
\hline \multicolumn{5}{|c|}{ Dependent variable: CT $1500 \mu \mathrm{m}$ nasal of the fovea } \\
\hline$\Delta \mathrm{CT}$ V2-V1 & 6.563 & .022 & 0.950 & 12.176 \\
\hline Age & -1.586 & .021 & -2.932 & -0.240 \\
\hline Axial length & -24.913 & .001 & -39.606 & -10.219 \\
\hline \multicolumn{5}{|c|}{ Dependent variable: CT $500 \mu \mathrm{m}$ superior of the fovea } \\
\hline$\Delta \mathrm{CT}$ V2-V1 & 9.398 & .004 & 2.950 & 15.847 \\
\hline Age & -1.630 & .009 & -2.845 & -0.414 \\
\hline Axial length & -19.259 & .004 & -32.541 & -5.976 \\
\hline \multicolumn{5}{|c|}{ Dependent variable: CT $1000 \mu \mathrm{m}$ superior of the fovea } \\
\hline$\Delta \mathrm{CT}$ V2-V1 & 10.728 & .003 & 3.625 & 17.832 \\
\hline Age & -1.877 & .003 & -3.103 & -0.652 \\
\hline Axial length & -17.656 & .010 & -31.039 & -4.274 \\
\hline \multicolumn{5}{|c|}{ Dependent variable: CT $1500 \mu \mathrm{m}$ superior of the fovea } \\
\hline$\Delta \mathrm{CT}$ V2-V1 & 9.311 & .006 & 2.701 & 15.920 \\
\hline Age & -1.744 & .006 & -2.983 & -0.505 \\
\hline Axial length & -20.191 & .003 & -33.717 & -6.665 \\
\hline \multicolumn{5}{|c|}{ Dependent variable: CT $500 \mu \mathrm{m}$ inferior of the fovea } \\
\hline$\Delta \mathrm{CT}$ V2-V1 & 5.019 & .167 & -2.100 & 12.139 \\
\hline Age & -1.902 & .001 & -3.049 & -0.755 \\
\hline Axial length & -15.741 & .014 & -28.262 & -3.220 \\
\hline \multicolumn{5}{|c|}{ Dependent variable: CT $1000 \mu \mathrm{m}$ inferior of the fovea } \\
\hline$\Delta \mathrm{CT}$ V2-V1 & 6.388 & .063 & -0.351 & 13.128 \\
\hline Age & -2.246 & .001 & -3.537 & -0.956 \\
\hline Axial length & -18.810 & .009 & -32.902 & -4.718 \\
\hline \multicolumn{5}{|c|}{ Dependent variable: CT $1500 \mu \mathrm{m}$ inferior of the fovea } \\
\hline$\Delta \mathrm{CT}$ V2-V1 & 3.301 & .326 & -3.291 & 9.893 \\
\hline Age & -2.539 & $<.001$ & -3.862 & -1.215 \\
\hline Axial length & -20.040 & .011 & -35.424 & -4.656 \\
\hline \multicolumn{5}{|c|}{$\mathrm{CT}=$ choroidal thickness; $\mathrm{V}=$ visit. } \\
\hline \multicolumn{5}{|c|}{$P$ values were obtained by generalized linear mixed-effects models. } \\
\hline \multicolumn{5}{|c|}{$\begin{array}{l}{ }^{a} \text { Reference categories: measurement of } \mathrm{CT} \text { at } \mathrm{V} 1 ; \Delta \mathrm{CT} \mathrm{V} 2-\mathrm{V} 1 \text { corresponds to the mean difference of } \mathrm{CT} \text { measurements between visit } 2 \text { and } \\
\text { visit } 1 .\end{array}$} \\
\hline
\end{tabular}


RT

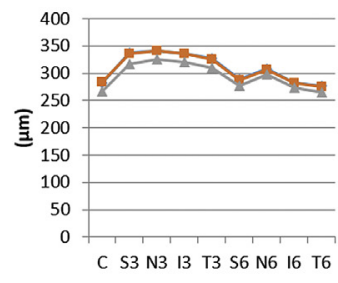

IPL

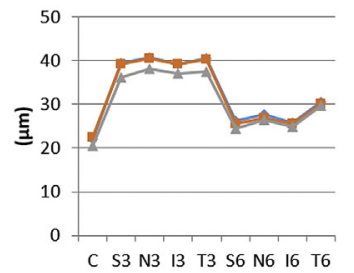

ONL

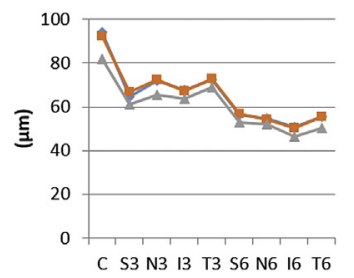

RNFL
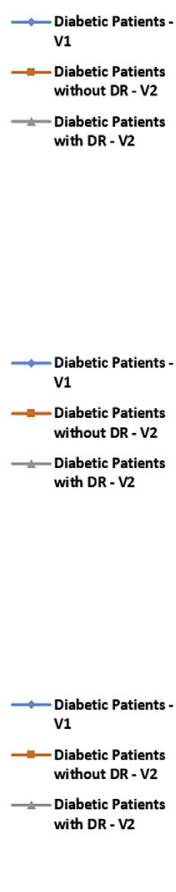

INL

PR
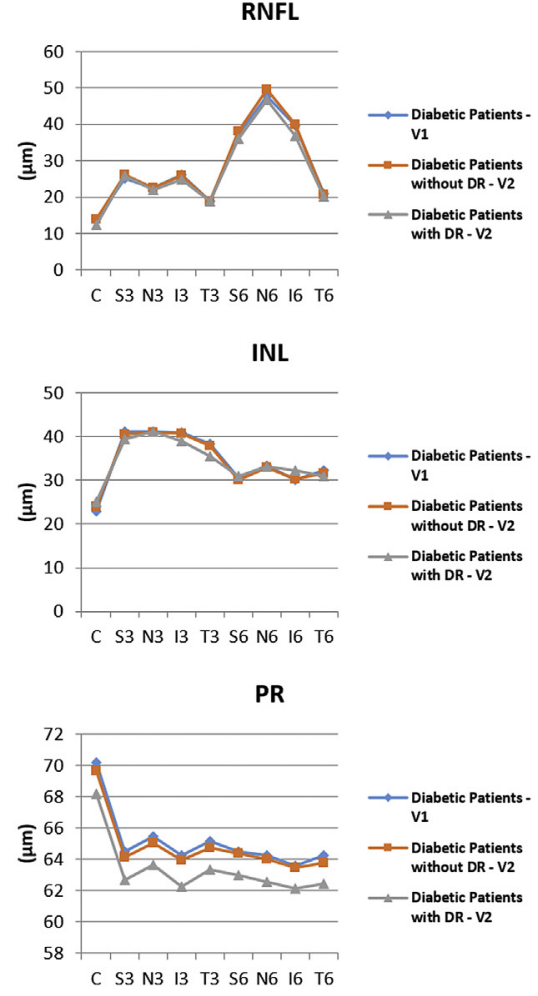

GCL

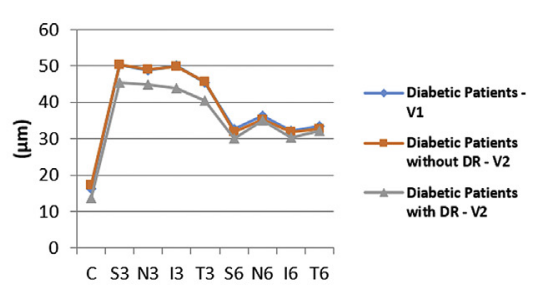

OPL

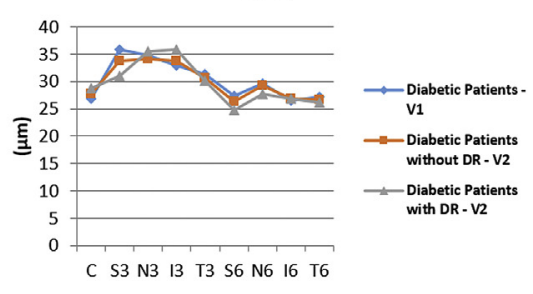

RPE

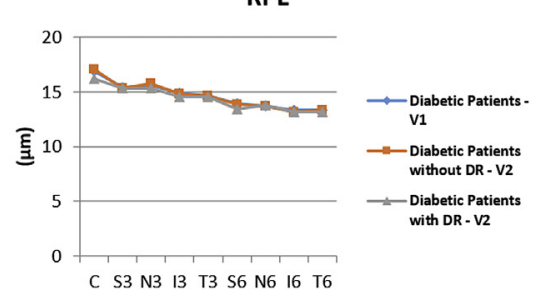

FIGURE 5. Graphs showing retinal layer thickness at visits 1 (V1) and 2 (V2).

\section{RESULTS}

- PATIENT DEMOGRAPHICS AND CLINICAL CHARACTERISTICS: A total of 125 diabetic patients with type $2 \mathrm{DM}$ without DR (63 male) were included in this study. After 12 months, these patients were asked to return for a second visit, as per protocol. Of these initial 125 patients, 19 missed the second appointment (when contacted, 18 did not justify their absence, and 1 had died). Of the remaining 106, 3 presented epiretinal membranes in OCT images and were thus excluded from further analysis. Overall, the attrition rate was $17.6 \%(\mathrm{n}=22)$. Of the 103 diabetic patients who completed the study, 9 developed DR (8.7\%) (Figure 4).

Demographic, clinical, and ophthalmologic characteristics, except for choroidal and retinal layer thickness, from both visits (V1 and V2) are presented in Table 1.

- ANALYSIS OF CHOROIDAL THICKNESS: At both visits, the overall CT distribution over the 4 quadrants maintained the same pattern, with higher values in the superior quadrants than in the inferior quadrants, as well as in temporal compared to nasal quadrants (Table 2). In V2, at all locations, the CT was higher for diabetic patients without DR than for diabetic patients who developed DR. However, this difference was not statistically significant (230-280 $\mu \mathrm{m}$ vs 217-270 $\mu \mathrm{m}$ ) (Table 2).
Results of the multiple regression analysis, after Bonferroni corrections, showed that the CT was greater, between 10 and $17 \mu \mathrm{m}$, in V2 than in V1, at almost half of the locations (500, 1000, and $1500 \mu \mathrm{m}$ temporal; 500 and $1000 \mu \mathrm{m}$ nasal; and $1000 \mu \mathrm{m}$ superior to the fovea) $(P<.001-.003)$ (Table 3$)$.

In these models, it was also observed that CT was negatively associated with age at 9 locations and with axial length at 4 locations $(P<.004)$. For each year of increase in lifespan, the CT mean values of diabetic patients decreased between 1.63 and $2.54 \mu \mathrm{m}$. Similarly, for each millimeter increase in the axial length of the eyeball, the CT mean values decreased from 17 to $25 \mu \mathrm{m}$ (Table 3).

- ANALYSIS OF RETINAL LAYER THICKNESS: At V2, the group of patients who developed DR showed significantly lower values for overall RT (C, S3, T3, and N3 sectors, $P=.009-.034)$, GCL (C sector, $P=.014)$, OPL (S6 sector, $P=.032$ ), and $\mathrm{ONL}(\mathrm{C}$ sector, $P=.035)$ (Figure 5).

After Bonferroni corrections, the results of the multiple regression analysis showed that, at visit $\mathrm{V} 2$ with respect to $\mathrm{V} 1$, there was a statistically significant increase in the RNFL thickness in only 1 sector (sector S3) and a decrease in the thickness of the GCL (I3 and N6 sectors), IPL (S6 and N6 sectors), INL (T6 and N6 sectors), and 
TABLE 4. Multivariable Regression Model Results for Overall Retinal Thickness

\begin{tabular}{|c|c|c|c|c|}
\hline \multicolumn{3}{|c|}{ Coefficient } & \multicolumn{2}{|c|}{ 95\% Confidence } \\
\hline Model $^{a}$ & Estimate & $P$ Value & & \\
\hline \multicolumn{5}{|c|}{ Dependent variable: overall $\mathrm{RT}$ at sector S3 } \\
\hline$\Delta$ Overall RT V2-V1 & -2.129 & $<.001$ & -2.994 & -1.264 \\
\hline Sex & 9.707 & .004 & 3.179 & 16.235 \\
\hline Diabetic retinopathy & -15.740 & .004 & -26.568 & -4.911 \\
\hline IOP & 0.747 & .021 & 0.111 & 1.383 \\
\hline Axial length & -7.193 & $<.001$ & -11.075 & -3.310 \\
\hline \multicolumn{5}{|c|}{ Dependent variable: overall RT at sector $\mathrm{T} 3$} \\
\hline$\Delta$ Overall RT V2-V1 & -1.947 & .001 & -3.052 & -0.842 \\
\hline Sex & 10.537 & .001 & 4.319 & 16.756 \\
\hline Diabetic retinopathy & -13.354 & .011 & -23.601 & -3.108 \\
\hline IOP & 0.923 & .011 & 0.213 & 1.633 \\
\hline Axial length & -5.093 & .007 & -8.765 & -1.421 \\
\hline \multicolumn{5}{|c|}{ Dependent variable: overall RT at sector I3 } \\
\hline$\Delta$ Overall RT V2-V1 & -1.922 & $<.001$ & -2.752 & -1.093 \\
\hline Sex & 6.934 & .030 & 0.680 & $13-188$ \\
\hline Diabetic retinopathy & -13.195 & .014 & -23.753 & -2.636 \\
\hline Axial length & -5.151 & .008 & -8.941 & -1.362 \\
\hline \multicolumn{5}{|c|}{ Dependent variable: overall RT at sector N3 } \\
\hline$\Delta$ Overall RT V2-V1 & -1.738 & $<.001$ & -2.665 & -0.811 \\
\hline Diabetic retinopathy & -13.038 & .022 & -24.229 & -1.848 \\
\hline \multicolumn{5}{|c|}{ Dependent variable: overall RT at sector $\mathrm{S} 6$} \\
\hline$\Delta$ Overall RT V2-V1 & -2.708 & $<.001$ & -3.981 & -1.436 \\
\hline Age & -0.467 & .002 & -0.763 & -0.171 \\
\hline Spherical equivalent & 2.686 & .004 & 0.840 & 4.532 \\
\hline \multicolumn{5}{|c|}{ Dependent variable: overall RT at sector T6 } \\
\hline$\Delta$ Overall RT V2-V1 & -3.256 & $<.001$ & -5.055 & -1.457 \\
\hline Sex & -0.309 & .021 & -0.571 & -0.046 \\
\hline Age & 6.079 & .014 & 1.225 & 10.932 \\
\hline IOP & 1.082 & .003 & 0.372 & 1.791 \\
\hline Spherical equivalent & 2.036 & .015 & 0.403 & 3.669 \\
\hline \multicolumn{5}{|c|}{$\begin{array}{l}\mathrm{IOP}=\text { intraocular pressure; } \mathrm{RT}=\text { retinal thickness; } \mathrm{V}=\text { visit. } \\
P \text { values were obtained by generalized linear mixed-effects models. } \\
{ }^{a} \text { Reference categories: measurement of the overall } \mathrm{RT} \text { at } \mathrm{V} 1 ; \Delta \text { overall } \mathrm{RT} V 2-\mathrm{V} 1 \text { corresponds to the mean difference of the overall } \mathrm{RT} \text { be- } \\
\text { ween visit } 2 \text { and visit } 1 .\end{array}$} \\
\hline
\end{tabular}

OPL ( $\mathrm{S} 6$ sector), as well as a decrease in the overall RT (S3, N3, I3, S6, and T6 sectors) $(P<.001)$ (Tables 4 and 5). After 1 year, the overall RT mean values decreased from 1.74 to $3.26 \mu \mathrm{m}$ in diabetic patients, whether or not they developed DR.

The existence of a visible diabetic retinopathy was negatively associated with the overall RT (central, S3, T3, I3, and N3 sectors) ( $P=.004-.024)$, ONL (T6 and I6 sectors) $(P=.007$ and $P=.009)$, and $P R$ layer (N6 sector) $(P=.038)$ (Tables 4 and 5$)$. In the span of just 1 year, the presence of DR decreased the overall RT mean values, in the locations specified, between 13.04 and $16.63 \mu \mathrm{m}$. However, the presence or absence of DR lost statistical significance for these layers and sectors after Bonferroni correction.

\section{DISCUSSION}

THIS LONGITUDINAL STUDY OF 125 TYPE 2 DIABETIC patients without DR showed that after 1 year, independent of the development of DR, the CT increased between 10 and $17 \mu \mathrm{m}(P<.001-.003)$, and there was a decrease in the GCL (I3 and N6 sectors), IPL (S6 and N6 sectors), INL (T6 and N6 sectors), OPL (S6 sector), and overall RT (S3, N3, I3, S6, and T6 sectors) $(P<.001)$.

Several studies have analyzed the CT in diabetic patients without DR, although the results have been contradictory. Esmaeelpour and associates and Querques and associates found that choroidal thinning was independent of disease stage, even in diabetic patients without DR. ${ }^{20-23}$ In 
TABLE 5. Multivariable Regression Model Results for Retinal Nerve Fiber, Ganglion Cell, Inner Nuclear, Outer Plexiform, Outer Nuclear, and Photoreceptor Layers

\begin{tabular}{|c|c|c|c|c|}
\hline Model $^{a}$ & \multicolumn{2}{|l|}{ Coefficient } & \multicolumn{2}{|c|}{ 95\% Confidence } \\
\hline \multicolumn{5}{|c|}{ Dependent variable: RNFL thickness at sector S3 } \\
\hline$\Delta$ RNFL thickness V2-V1 & 0.883 & $<.001$ & 0.435 & 1.332 \\
\hline \multicolumn{5}{|c|}{ Dependent variable: GCL thickness at sector I3 } \\
\hline$\Delta \mathrm{GCL}$ thickness $\mathrm{V} 2-\mathrm{V} 1$ & -0.796 & $<.001$ & -1.112 & -0.480 \\
\hline Age & -0.220 & $<.001$ & -0.335 & -0.105 \\
\hline \multicolumn{5}{|c|}{ Dependent variable: GCL thickness at sector N6 } \\
\hline$\Delta \mathrm{GCL}$ thickness $\mathrm{V} 2-\mathrm{V} 1$ & -0.932 & $<.001$ & -1.431 & -0.433 \\
\hline Age & -0.164 & $<.001$ & -0.251 & -0.077 \\
\hline \multicolumn{5}{|c|}{ Dependent variable: IPL thickness at sector S6 } \\
\hline$\Delta \mathrm{IPL}$ thickness $\mathrm{V} 2-\mathrm{V} 1$ & -0.738 & $<.001$ & -1.085 & -0.391 \\
\hline Age & -0.101 & .001 & -0.158 & -0.044 \\
\hline \multicolumn{5}{|c|}{ Dependent variable: IPL thickness at sector N6 } \\
\hline$\Delta \mathrm{IPL}$ thickness $\mathrm{V} 2-\mathrm{V} 1$ & -0.883 & $<.001$ & -1.315 & -0.451 \\
\hline Age & -0.125 & $<.001$ & -0.193 & -0.057 \\
\hline \multicolumn{5}{|c|}{ Dependent variable: INL thickness at sector T6 } \\
\hline$\Delta \mathrm{INL}$ thickness $\mathrm{V} 2-\mathrm{V} 1$ & -0.685 & $<.001$ & -1.007 & -0.362 \\
\hline Age & -0.050 & .044 & -0.099 & -0.001 \\
\hline Spherical equivalent & 0.318 & .041 & 0.013 & 0.624 \\
\hline \multicolumn{5}{|c|}{ Dependent variable: INL thickness at sector N6 } \\
\hline$\Delta \mathrm{INL}$ thickness $\mathrm{V} 2-\mathrm{V} 1$ & -0.544 & $<.001$ & -0.850 & -0.238 \\
\hline Age & -0.059 & .041 & -0.115 & -0.003 \\
\hline \multicolumn{5}{|c|}{ Dependent variable: OPL thickness at sector S6 } \\
\hline$\Delta \mathrm{OPL}$ thickness $\mathrm{V} 2-\mathrm{V} 1$ & -1.039 & $<.001$ & -1.607 & -0.471 \\
\hline \multicolumn{5}{|c|}{ Dependent variable: ONL thickness at sector T6 } \\
\hline$\Delta \mathrm{ONL}$ thickness $\mathrm{V} 2-\mathrm{V} 1$ & -0.534 & .096 & -1.163 & 0.095 \\
\hline Diabetic retinopathy & -4.931 & .007 & -8.523 & -1.340 \\
\hline Axial length & -1.676 & .008 & -2.907 & -0.446 \\
\hline \multicolumn{5}{|c|}{ Dependent variable: ONL thickness at sector 16} \\
\hline$\Delta \mathrm{ONL}$ thickness $\mathrm{V} 2-\mathrm{V} 1$ & -0.728 & .008 & -1.264 & -0.193 \\
\hline Diabetic retinopathy & -4.382 & .009 & -7.670 & -1.095 \\
\hline Axial length & -2.453 & $<.001$ & -3.580 & -1.327 \\
\hline \multicolumn{5}{|c|}{ Dependent variable: PR layer thickness at sector N6 } \\
\hline$\Delta \mathrm{PR}$ layer thickness $\mathrm{V} 2-\mathrm{V} 1$ & -0.408 & .013 & -0.729 & -0.087 \\
\hline Sex & 0.686 & .040 & 0.030 & 1.341 \\
\hline Diabetic retinopathy & -1.229 & .038 & -2.388 & -0.069 \\
\hline \multicolumn{5}{|c|}{$\begin{array}{l}\mathrm{GCL}=\text { ganglion cell layer; INL }=\text { inner nuclear layer; } \mathrm{ONL}=\text { outer nuclear layer; } \mathrm{OPL}=\text { outer plexiform layer; } \mathrm{PR}=\text { photoreceptor; } \\
\mathrm{RNFL}=\text { retinal nerve fiber layer; } \mathrm{V}=\text { visit. } \\
P \text { values were obtained by generalized linear mixed-effects models. } \\
{ }^{\text {a }} \text { Reference categories: measurement of the RNFL, GCL, IPL, INL, OPL, ONL, or PR layer thickness at V1; } \triangle \mathrm{RNFL,} \mathrm{GCL,} \mathrm{IPL,} \mathrm{INL,} \mathrm{OPL,} \mathrm{ONL,} \\
\text { or PR layer thickness V2-V1 corresponds to the mean difference of the RNFL, GCL, IPL, INL, OPL, ONL or PR layer thickness between visit } 2 \\
\text { and visit } 1 .\end{array}$} \\
\hline
\end{tabular}

contrast, $\mathrm{Xu}$ and associates, in a Beijing study that included 246 diabetic subjects, 23 of whom had DR, reported a thicker subfoveal choroid associated with DM. ${ }^{24}$ However, this difference was not related to the presence or stage of DR after adjusting for various confounders. ${ }^{24}$ Vujosevic and associates found no significant difference in CT between diabetic patients and controls. ${ }^{25}$ Although these findings are divergent, it should be noted that the samples were small for each DR stage, and the results were therefore insufficient for a meaningful multivariable analysis. Moreover, there are numerous physiologic variables such as axial length, refractive error, IOP, diurnal variation, and different drugs that might affect CT, and these factors should be considered in such studies.

In our study, the increased CT observed in diabetic patients without DR after 1 year may correspond to the presence of a choroidal vasculopathy. Choroidal edema or vascular dilation with increased rigidity of the blood vessels may be responsible for this increase in CT. However, the autoregulation of the choroid remains controversial. ${ }^{26}$ In diabetic patients, Nagaoka and associates ${ }^{13}$ showed that 
there was decreased choroidal blood flow, even before visible DR was present.

The trend for a thinning choroid in diabetic patients who develop DR compared with patients without DR (230-280 $\mu \mathrm{m}$ vs $217-270 \mu \mathrm{m}$ ) may correspond to the beginning of the vascular atrophy phase. Kim and associates $^{27}$ and Vujosevic and associates ${ }^{25}$ showed that early DR was associated with a thinner choroid when compared with a control group. Future longitudinal studies with a larger sample of diabetic patients with DR will be required to confirm this result.

In diabetic patients, regardless of the presence of retinopathy, we documented a reduction in overall RT after 1 year, as well as a reduction in the thickness of the inner layers (GCL, IPL, and INL), which may be related to the early neurodegenerative phase described in previous studies. ${ }^{9,28,29}$ The patients who developed DR, although few in number, also showed a statistically significant decrease in overall RT (C, S3, T3, and N3 sectors), GCL (C sector), OPL (S6 sector), and ONL (C sector), which may correspond to the continuation of neurodegeneration that had started before the presence of retinopathy. Retinal neurodegeneration is characterized as a consequence of neural apoptosis, reactive gliosis, glutamate excitotoxicity, a decrease in neuroprotective factors, and the impairment of neurovascular coupling. ${ }^{9}$ Different studies using SDOCT have reported a decrease in RNFL and GCL/IPL thickness in diabetic patients without DR. ${ }^{30-32}$ Sohn and associates quantified the decrease in the inner retinal layer thickness over time in 45 diabetic patients with or without mild nonproliferative $\mathrm{DR}$ and reported a progressive decrease in RNFL of $0.25 \mu \mathrm{m} /$ year and in GCL/IPL of $0.29 \mu \mathrm{m} /$ year over a period of 4 years, regardless of $\mathrm{HbA} 1 \mathrm{c}$, age, or sex. ${ }^{33}$

Interestingly, in this study the variable retinopathy was negatively associated with the overall RT (central, S3, T3, I3, and N3 sectors), ONL (T6 and I6 sectors), and PR layer (N6 sector). In the span of just 1 year, the presence of DR decreased the overall RT in the studied locations between 13.04 and $16.63 \mu \mathrm{m}$.

Our study had some limitations. First, CT measurements were obtained manually. However, this manual technique previously showed high intraobserver and interobserver reproducibility. ${ }^{34}$ Second, retinal measurements were performed with automatic software. However, manual correction was performed by an ophthalmologist masked to the patients' diagnosis when the segmentation was inaccurate. Finally, an inherent limitation of this type of study concerns the disease duration, because the onset of the disease (particularly type 2 diabetes) is insidious, and patients can only report it once the diagnosis can been made based on clinical and analytical findings. Accordingly, disease duration may have been underestimated.

In conclusion, in diabetic patients without DR at the 1year follow-up point, we observed overall thickening of the choroid and decreases in the thickness of the inner retinal layers (GCL, IPL, and INL) and overall RT. Thus, when patients develop DR, the choroid begins to decrease along with the overall RT and PR layer thickness.

FUNDING/SUPPORT: NO FUNDING OR GRANT SUPPORT. FINANCIAL DISCLOSURES: THE FOLLOWING AUTHORS HAVE NO financial disclosures: Joana Tavares Ferreira, Rita Proença, Marta Alves, Arnaldo Dias-Santos, Bruno Oliveira Santos, João Paulo Cunha, Ana Luísa Papoila, and Luís Abegão Pinto. All authors attest that they meet the current ICMJE criteria for authorship.

Special thanks to Dr Gonçalo Agudo, of the Department of Ophthalmology of the Central Hospital Lisbon Center, Lisbon, Portugal, for his help in obtaining tomographic images.

\section{REFERENCES}

1. Klein BEK. Overview of epidemiologic studies of diabetic retinopathy. Ophthalmic Epidemiol 2007;14(4): 179-183.

2. International Diabetes Federation (IDF). IDF Diabetes Atlas. 7th edition. 2015, http://www.diabetesatlas.org/.

3. Dutra Medeiros M, Mesquita E, Papoila AL, Genro V, Raposo JF. First diabetic retinopathy prevalence study in Portugal: RETINODIAB Study-Evaluation of the screening programme for Lisbon and Tagus Valley region. Br J Ophthalmol 2015;99(10):1328-1333.

4. Dutra Medeiros M, Mesquita E, Gardete-Correia L, et al. First incidence and progression study for diabetic retinopathy in Portugal, the RETINODIAB study: evaluation of the screening program for Lisbon region. Ophthalmology 2015; 122(12):2473-2481.

5. Pelletier EM, Shim B, Ben-Joseph R, Caro JJ. Economic outcomes associated with microvascular complications of type 2 diabetes mellitus: results from a US claims data analysis. Pharmacoeconomics 2009;27(6):479-490.

6. Lee LJ, Yu AP, Cahill KE, et al. Direct and indirect costs among employees with diabetic retinopathy in the United States. Curr Med Res Opin 2008;24(5):1549-1559.

7. Nunes S, Ribeiro L, Lobo C, Cunha-Vaz J. Three different phenotypes of mild nonproliferative diabetic retinopathy with different risks for development of clinically significant macular edema. Invest Ophthalmol Vis Sci 2013;54(7): 4595-4604.

8. Grading diabetic retinopathy from stereoscopic color fundus photographs-an extension of the modified Airlie House classification. ETDRS report number 10. Early Treatment Diabetic Retinopathy Study Research Group. Ophthalmology 1991;98(5 Suppl):786-806.

9. Barber AJ, Lieth E, Khin SA, Antonetti DA, Buchanan AG, Gardner TW. Neural apoptosis in the retina during experimental and human diabetes. Early onset and effect of insulin. J Clin Invest 1998;102(4):783-791. 
10. Carrasco E, Hernández C, Miralles A, Huguet P, Farrés J, Simó R. Lower somatostatin expression is an early event in diabetic retinopathy and is associated with retinal neurodegeneration. Diabetes Care 2007;30(11):2902-2908.

11. Carrasco E, Hernández C, de Torres I, Farrés J, Simó R. Lowered cortistatin expression is an early event in the human diabetic retina and is associated with apoptosis and glial activation. Mol Vis 2008;14:1496-1502.

12. Garcia-Ramírez M, Hernández C, Villarroel M, et al. Interphotoreceptor retinoid-binding protein (IRBP) is downregulated at early stages of diabetic retinopathy. Diabetologia 2009; 52(12):2633-2641.

13. Nagaoka T, Kitaya N, Sugawara R, et al. Alteration of choroidal circulation in the foveal region in patients with type 2 diabetes. $\mathrm{Br}$ J Ophthalmol 2004;88(8): 1060-1063.

14. Spaide RF, Koizumi H, Pozzoni MC, Pozonni MC. Enhanced depth imaging spectral-domain optical coherence tomography. Am J Ophthalmol 2008;146(4):496-500.

15. Ctori I, Huntjens B. Repeatability of foveal measurements using Spectralis optical coherence tomography segmentation software. PLoS One 2015;10(6):e0129005.

16. Simó R, Hernández C. Neurodegeneration in the diabetic eye: new insights and therapeutic perspectives. Trends Endocrinol Metab 2014;25(1):23-33.

17. Tavares Ferreira J, Alves M, Dias-Santos A, et al. Retinal neurodegeneration in diabetic patients without diabetic retinopathy. Invest Ophthalmol Vis Sci 2016;57(14):6455-6460.

18. Jeoung JW, Kim T-W, Weinreb RN, Kim SH, Park KH, Kim DM. Diagnostic ability of spectral-domain versus timedomain optical coherence tomography in preperimetric glaucoma. J Glaucoma 2014;23(5):299-306.

19. Photocoagulation for diabetic macular edema. Early Treatment Diabetic Retinopathy Study report number 1. Early Treatment Diabetic Retinopathy Study research group. Arch Ophthalmol 1985;103(12):1796-1806.

20. Esmaeelpour M, Brunner S, Shahrezaei S, et al. Choroidal thinning in diabetes type 1 detected by 3-dimensional $1060 \mathrm{~nm}$ optical coherence tomography. Invest Ophthalmol Vis Sci 2012;53(11):6803-6809.

21. Esmaeelpour M, Povazay B, Hermann B, et al. Three-dimensional 1060-nm OCT: choroidal thickness maps in normal subjects and improved posterior segment visualization in cataract patients. Invest Ophthalmol Vis Sci 2010;51(10): 5260-5266.
22. Esmaeelpour M, Považay B, Hermann B, et al. Mapping choroidal and retinal thickness variation in type 2 diabetes using three-dimensional 1060-nm optical coherence tomography. Invest Ophthalmol Vis Sci 2011;52(8):5311-5316.

23. Querques G, Lattanzio R, Querques L, et al. Enhanced depth imaging optical coherence tomography in type 2 diabetes. Invest Ophthalmol Vis Sci 2012;53(10):6017-6024.

24. Xu J, Xu L, Du KF, et al. Subfoveal choroidal thickness in diabetes and diabetic retinopathy. Ophthalmology 2013;120(10): 2023-2028.

25. Vujosevic S, Martini F, Cavarzeran F, Pilotto E, Midena E. Macular and peripapillary choroidal thickness in diabetic patients. Retina 2012;32(9):1781-1790.

26. Muir ER, Rentería RC, Duong TQ. Reduced ocular blood flow as an early indicator of diabetic retinopathy in a mouse model of diabetes. Invest Ophthalmol Vis Sci 2012;53(10): 6488-6494.

27. Kim JT, Lee DH, Joe SG, Kim JG, Yoon YH. Changes in choroidal thickness in relation to the severity of retinopathy and macular edema in type 2 diabetic patients. Invest Ophthalmol Vis Sci 2013;54(5):3378-3384.

28. Lieth E, Gardner TW, Barber AJ, Antonetti DA. Penn State Retina Research Group. Retinal neurodegeneration: early pathology in diabetes. Clin Experiment Ophthalmol 2000;28(1):3-8.

29. Barber AJ, Gardner TW, Abcouwer SF. The significance of vascular and neural apoptosis to the pathology of diabetic retinopathy. Invest Ophthalmol Vis Sci 2011;52(2):1156-1163.

30. Vujosevic S, Midena E. Retinal layers changes in human preclinical and early clinical diabetic retinopathy support early retinal neuronal and Müller cells alterations. J Diabetes Res 2013;2013:905058.

31. van Dijk HW, Verbraak FD, Kok PHB, et al. Decreased retinal ganglion cell layer thickness in patients with type 1 diabetes. Invest Ophthalmol Vis Sci 2010;51(7):3660-3665.

32. van Dijk HW, Verbraak FD, Kok PHB, et al. Early neurodegeneration in the retina of type 2 diabetic patients. Invest Ophthalmol Vis Sci 2012;53(6):2715-2719.

33. Sohn EH, van Dijk HW, Jiao C, et al. Retinal neurodegeneration may precede microvascular changes characteristic of diabetic retinopathy in diabetes mellitus. Proc Natl Acad Sci U S A 2016;113(19):E2655-E2664.

34. Shao L, Xu L, Chen CX, et al. Reproducibility of subfoveal choroidal thickness measurements with enhanced depth imaging by spectral-domain optical coherence tomography. Invest Ophthalmol Vis Sci 2013;54(1):230-233. 